\title{
CHAPTER 27
}

\section{MEASUREMENT OF COASTAL CURRENTS}

\author{
J. M. Zeigler \\ Department of Marine Sciences \\ University of Puerto Rico \\ Mayagllez, Puerto Rico \\ and \\ H. J. Tasha \\ Provincetown, Massachusetts
}

\begin{abstract}
Getting a drift buoy into and over the surf zone in rough weather has always been a problem. A cheap, coldpropellant rocket launcher using either compressed air from aqua-lung bottles or liquid carbon dioxide is admirably suited for hurling drift bottles to ranges of over 1,000 feet. This launcher weighs less than one hundred pounds and can be easily transported to places of difficult access such as cliffed or reefy coasts. The float package can be modified to include mid-depth drogues if that is desired. An example of work done by a single field operator illustrates the versatility of this technique.
\end{abstract}

Naval Mark II flares are useful for current tracing because they are easily obtained and can be set in arrays from aircraft. As they burn, however, they change their freeboard and are therefore more subject to wind drift than when they are lower in the water. Mark II flares were calibrated for wind drift with results given.

$A$ wind velocity profile between $5 / 8$ inches and 5 inches above the water surface was obtained from floating arrays of flares with the results given.

In their search for better ways to measure currents in or near the surf zone, the writers have developed improvements in some old methods, namely, methods which measure the rate of drift of floating objects.

The present work reports on a new technique which was developed wherein drift bottles were fired into the sea 
from a cold-propellant rocket launcher. The bottles, properly trimmed to float with less than an inch of neck exposed, were then tracked for a known time by theodolite. By this means one could measure the velocity of surface currents over a spectrum of sea states which otherwise would be too rough to work in.

Furthermore, the technique can be used especially well on rugged, cliffed or remote coasts which are awkward to reach. The writers consider this technique especially well-suited for reconnaissance.

\section{The launcher}

The rocket launcher is manufactured by Texaco Research Corp.; the system is named the Cricket. The launcher consists of an aluminum barrel 8 feet long that fits into a console in which a series of valves controls the pressure of carbon dioxide to be released into the base of the tube. This blast of carbon dioxide, up to 400 p.s.1., is in reality a booster charge used to hurl the rocket clear of the tube. The writers used compressed air from aqua-lung bottles instead of carbon dioxide because it was cheaper and more readily available at our field site. In this work we did not use the rockets but only the launcher and its booster much like a mortar or muzzle-loading cannon. A newspaper stuffed down the muzzle acted as wadding; the drift bottle rammed on top of it completed the charge. After some practice an operator could drop his bottle quite accurately at ranges up to 1300 or 1400 feet, which probably could be increased. The process of loading and firing took only two or three minutes.

There is no reason why the package fired cannot be modified to hold a mid-depth drogue as well as a surface drifter, thereby making it possible to take measurements of the current profile.

The launcher is portable, weighing only 90 pounds, easily set up, safe to use, store and transport, and cheap to operate. We have on one occasion had three drifters operational simultaneously. The number can be whatever the field party can handle without confusion. Weak points in the operation are loss of visibility in $f \circ g$ and rain, loss of range in strong winds, increasing loss of drifters as sea state becomes more frothy, and the requirement that the theodolite be of sufficient elevation above the sea that vertical angles can be measured easily.

The writers used this system as part of a program designed to separate wind-driven, wave-driven and tidaldriven components of the nearshore currents. Figure 1 


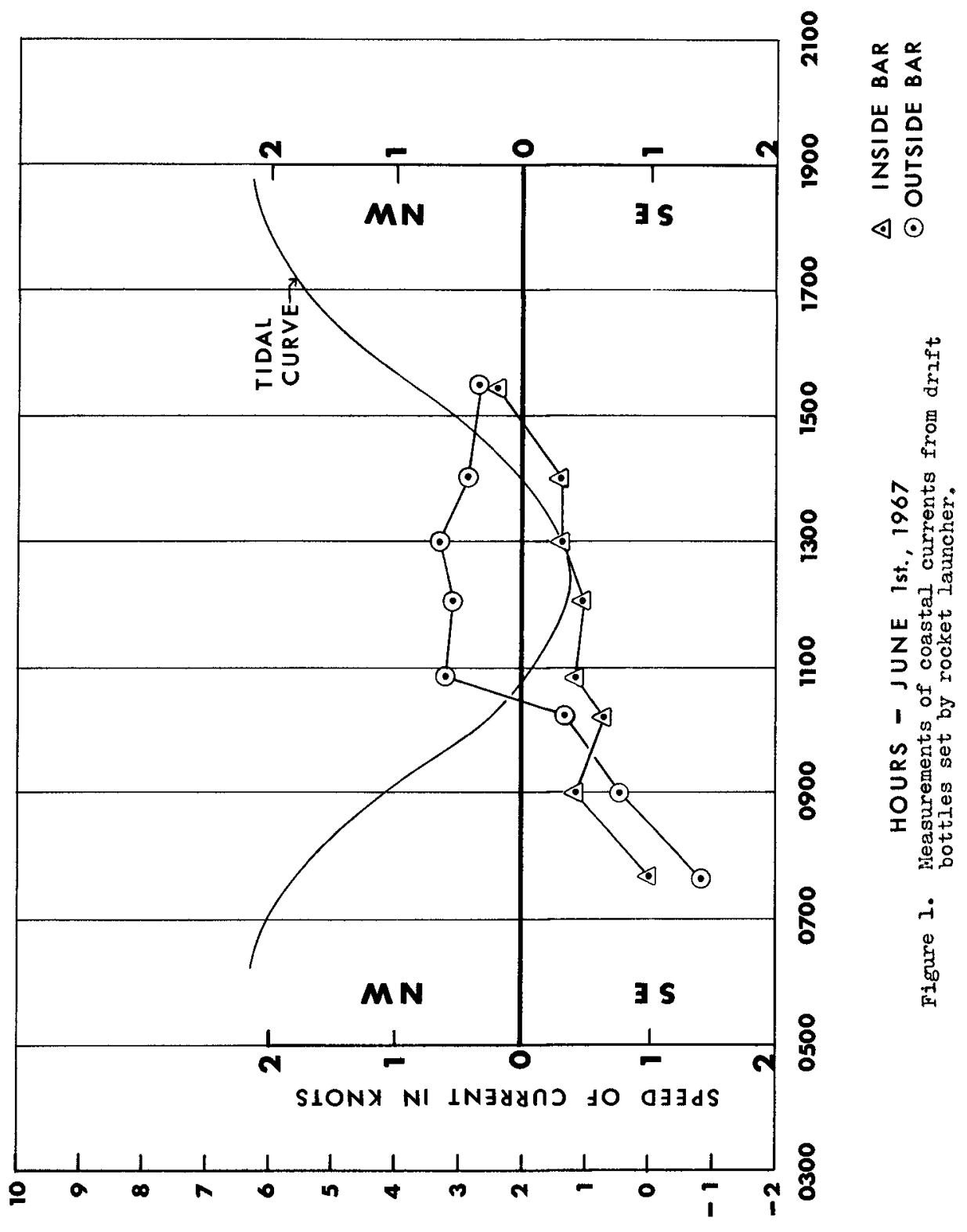

NOIIVA313 IVOII 


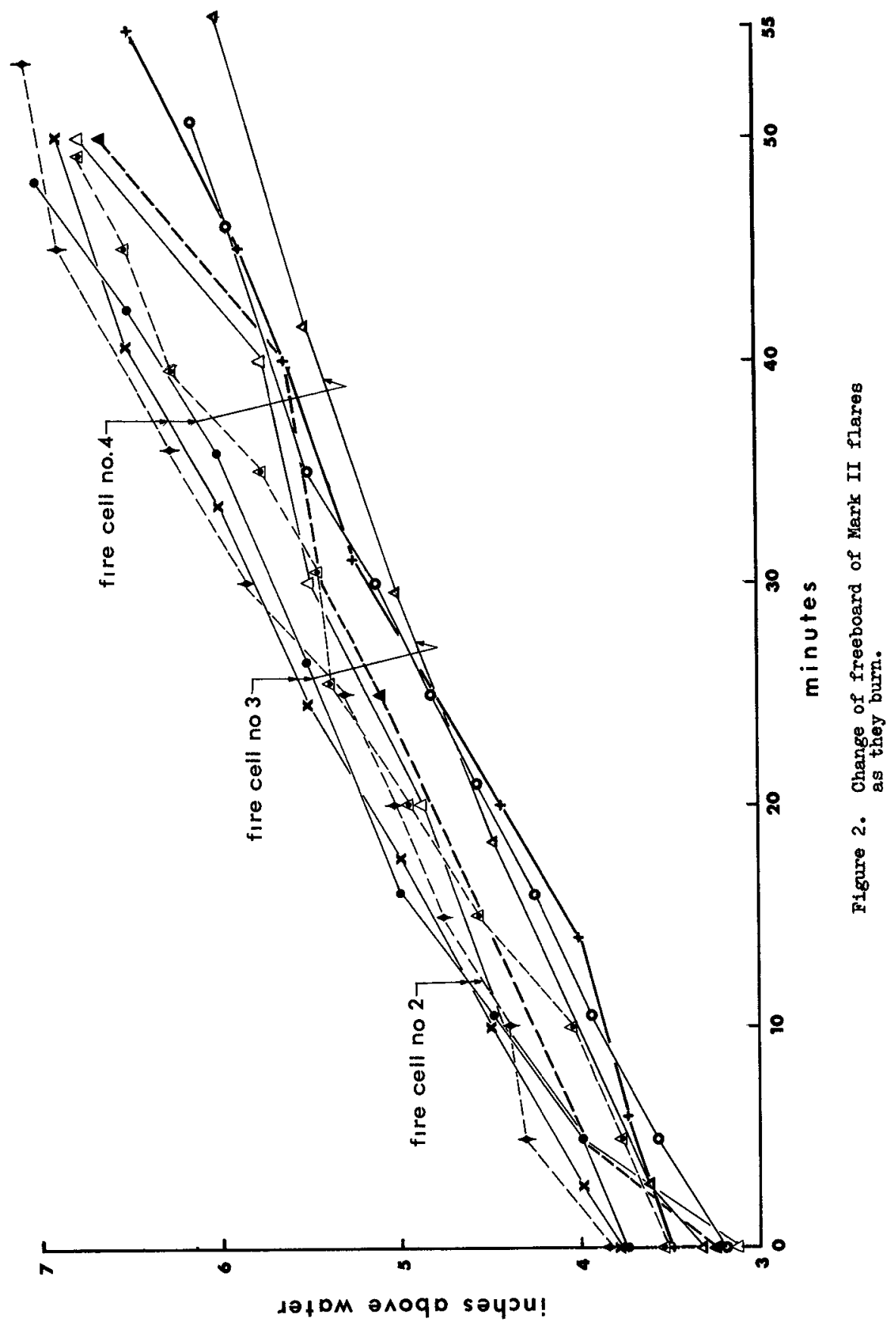




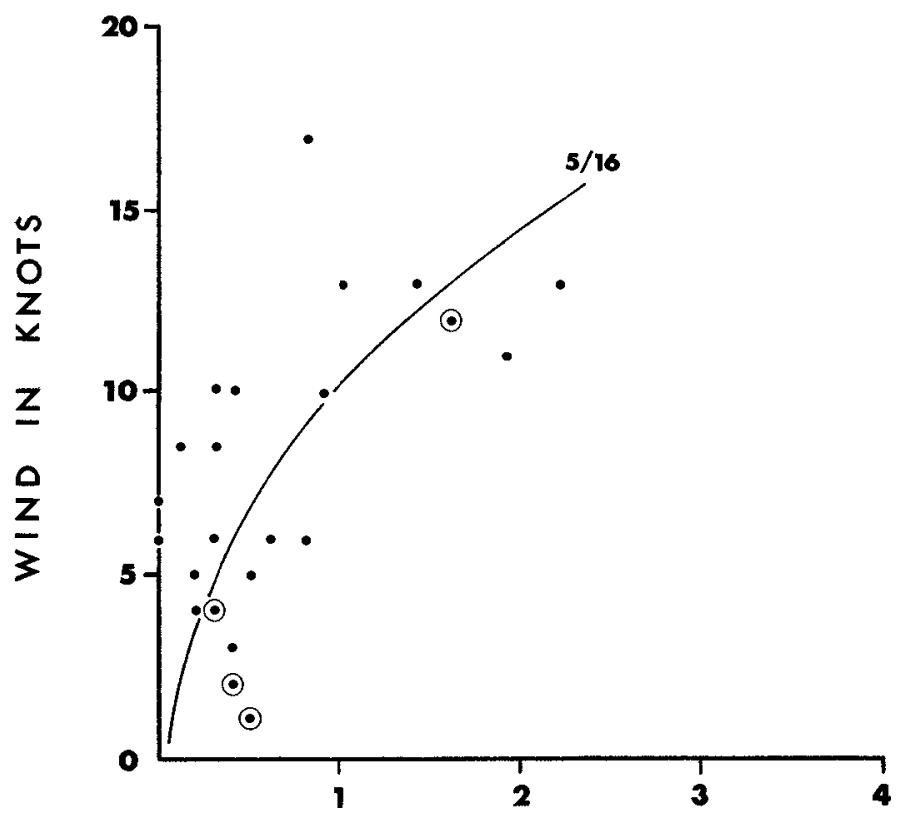

INCHES/SECOND

Figure 3. Drift of a flare with $5 / 8$ inch freeboard for various wind velocities. 


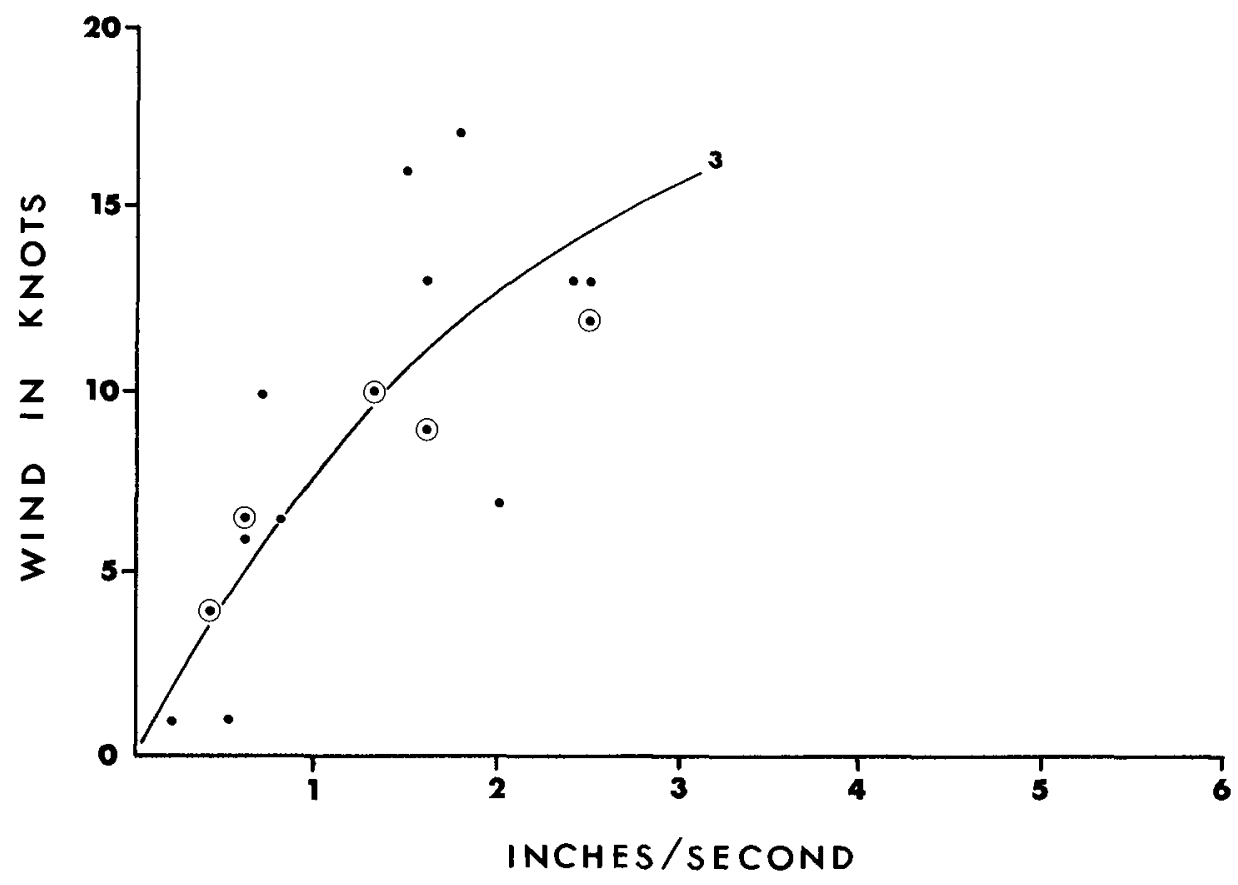

Figure 4. Drift of a flare with 3 inch freeboard for various wind velocities. 


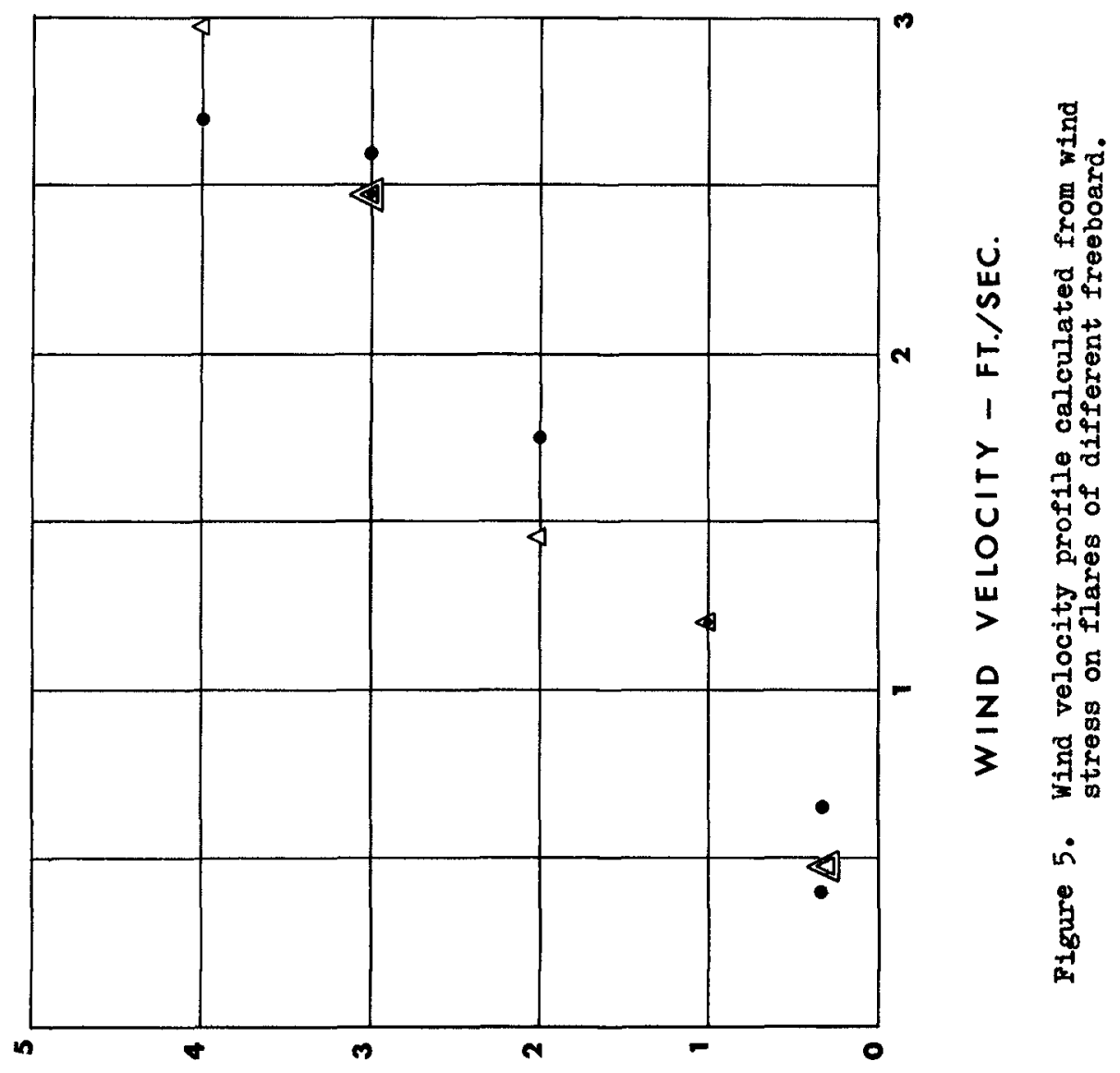

УヨI 
shows data taken on a single day by this technique; they are representative of all the rest. Considering that it is the work of a single observer who operated both launcher and theodolite, the cost per day is low. Yet, the observations obtalned are not easy to get using a crew, and they are literally impossible when the sea is up.

\section{Measurements}

Measurements were taken at Highland Iight beach, Cape Cod, Massachusetts, a location used by us for a variety of studies. The beach 18 about 200 feet wide separated from the nearshore bar by a low approximately 150 feet wide. The offshore bar lies 900 to 1300 feet from the low tide Iine.

Figure 1 shows the velocity and direction of currents inside and outside the bar as the tide changed. No attempt will be made in this paper to draw conclusions from these data because they represent part of another study. Our objective is simply to illustrate a use for this technique as an efficient tool in hard-to-reach waters.

\section{Use of flares as drogues}

Navy Mark II aerial flares are generally available to holders of naval contracts. These flares burn for approximately 53 minutes with a plume of white smoke. Because of their availability and ease in setting, the writers have used them in arrays to measure currents. We discovered that as the flare burns it rises higher into the air and wind drag on it becomes greater. Therefore, we calibrated these flares for wind drag. Figure 2 shows the change of freeboard as the flare burns. One can see that the flares inftially have a freeboard between 3 and 4 inches and that they change their freeboard linearly as they burn. In practice we pre-trim our flares to an initial freeboard of $5 / 8$ inch before using them.

Flares were calibrated in a coastal lagoon four feet deep with essentially no tidal currents. A post driven into the bottom marked the origin; floats pre-trimmed to have almost no scope were dropped to mark terminal points. Distance was measured by surveyor's chain, time with a stop watch, angle by an azimuth circle mounted on top of the prpe, and wind velocity by a Weston hand-held anemometer at two and five feet above the water surface. Groups of flares carefully trimmed to float with freeboards of $5 / 8,1,2,3,4$, and 5 inches were started at the origin and aliowed to drift. A mid-depth drogue was used to determine the direction and velocity of the current. The ratio of the surface area of the drogue to its float was approximately $1: 100$. These measurements were continued 
over a period of weeks until a sampling of drift caused by wind velocities between 2 and 20 knots was measured. Figures 3 and 4 show the drift due to wind blowing on naval aerial flares with freeboards of $5 / 8$ and 3 inches respectively.

The flares followed paths which for the most part indicated movement to the right of the observed wind rather than directly downwind. It was noted that this angle between wind and flare path was lowest when wind velocities were greater than nine miles per hour, and that the angle between flare path and wind direction was high when wind velocities were low. For example, the angle between flare drift path and wind direction was between zero and fourteen degrees (average 6 degrees) for wands greater than nine miles per hour, and the angle was between twenty-two and forty-eight degrees (average 36 degrees) for winds whose velocities were less than nine miles per hour. Out of fifty trials, the flares moved to the left of the wind direction only six times, and all of these were at times of very light winds. The results of our measurements coincided with the visual observations that wind direction and velocity were most difficult to obtain when winds were light. Observation of cat's-paws on the water showed much variation in wind direction when winds were light.

We concluded, in spite of the scatter in the data and the uncertainty of wind direction, that by using the regults given in figures four and five and the angles stated we can make meaningful corrections to the flare paths and velocities when we use them in the field.

\section{Wind velocity profile calculated from flare drifting}

As stated, the wind was measured at an elevation of five feet and two feet above the water with no observed reduction in velocity. Since several flares of different freeboards were drifted simultaneously in the same wind field, the wind velocity required to push a given flare of known area through the water at a measured velocity can be computed from the relationship of balanced forces of wind being opposed by water, assuming no acceleration is taking place after a short interval of time.

$$
\begin{aligned}
F_{\text {wind }} & = \\
\text { (wind) } \frac{C_{D} P_{A} V^{2} A_{A}}{2} & =\frac{F_{\text {water }}}{V^{2} \text { wind }}=\frac{\rho_{W} V_{W}{ }^{2} V_{W}{ }^{2}}{\rho_{A}^{A}} \text { (water) }
\end{aligned}
$$


$\mathrm{V}$ Velocity of wind acting at a point 0.793 of the freeboard measured upward from the water

$V_{W}$ Wind drift component of the flare through the water

$C_{D}$ Drag coefficient for flare of given dimensions

$A_{A}$ Cross-sectional area of flare exposed to wind

$A_{W}$ Cross-sectional area of the part of flare exposed to water

$Q A$ Density of air

Qw Density of water

The factor 0.793 is calculated as the point on the flare, measured upward from the water, at which the moments of force due to wind are balanced. These calculations were made for experiments done under the same wind velocity, thirteen miles per hour, where several flares were drifted at the same time. Figure 5 gives the wind velocity profiles caloulated from these measurements.

It is difficult to assess the exact meaning of the profile obtained because too many unknowns are involved. For example, we have no idea what forces were exerted by the orbital motions of waves, nor do we know the vertical motions of the flares and their upward and downward penetrations into the wind field. Gustiness was clearly observed at the water surface. On the other hand, the data were taken carefully and repeated runs plotted with remarkably little scatter. In spite of the unsteady conditions, one gets a uniform result.

Acknowledgements The writers wish to thank their colleagues, Dr. Robert Byrne, Dr. Graham Giese and Mr. William D. Athearn, for their assistance in this work both in the field and in the discussions which followed. 